\title{
Collectin-11/MASP Complex Formation Triggers Activation of the Lectin Complement Pathway - The Fifth Lectin Pathway Initiation Complex
}

\author{
Ying Jie Ma Mikkel-Ole Skjoedt Peter Garred \\ Laboratory of Molecular Medicine, Department of Clinical Immunology, Rigshospitalet, Faculty of Health Sciences, \\ University of Copenhagen, Copenhagen, Denmark
}

\section{Key Words}

CL-K1 · Collectin-11 • Complement activation •

Lectin pathway $\cdot$ MAP-1 $\cdot$ MASP-1 $\cdot$ MASP-2 $\cdot$ MASP-3

\begin{abstract}
Collectins and ficolins are important in the clearance of endogenous and exogenous danger materials. A new human collectin-11 was recently identified in low concentration in serum in complex with mannose-binding lectin (MBL)/ficolin-associated serine proteases. Collectin-11 binds to carbohydrate residues present on various microorganisms. Thus, we hypothesized that collectin-11 could be a novel initiation molecule in the lectin pathway of complement. We can show that collectin-11 associates with all the known MBL-associated serine proteases (MASP-1, MASP-2 and MASP-3) as well as the lectin complement pathway regulator MAP-1. Furthermore, we found that complex formation between recombinant collectin-11 and recombinant MASP-2 on Candida albicans leads to deposition of C4b. Native collectin-11 in serum mediated complement activation and deposition of $\mathrm{C} 4 \mathrm{~b}$ and $\mathrm{C} 3 \mathrm{~b}$, and formation of the terminal complement complex on C. albicans. Moreover, spiking collectin-11-depleted serum, which did not mediate complement activation, with recombinant collectin-11 restored the complement activation ca-
\end{abstract}

pability. These results define collectin-11 as the fifth recognition molecule in the lectin complement pathway in addition to MBL, ficolin-1, ficolin-2 and ficolin-3.

Copyright $\odot 2012$ S. Karger AG, Basel

\section{Introduction}

Pathogen-associated molecular pattern recognition by pattern recognition molecules is a central hallmark of innate immunity to eliminate invading pathogens via immune defense mechanisms, such as complement activation and opsonophagocytosis [1]. Collectins are members of the C-type lectin superfamily that recognize pathogenassociated molecular patterns exposed on pathogens, which facilitate opsonophagocytosis [2]. It comprises the classical C-type lectin superfamily consisting of mannose-binding lectin (MBL) and surfactant proteins $A$ and $\mathrm{D}$, all of which possess two structural characteristics, a collagen-like domain and a carbohydrate recognition domain (CRD), which are assembled into trimers and further organized into higher-order oligomeric structures [2]. Among these, MBL is the only collectin shown to be involved in lectin complement pathway activation, sharing this feature with the ficolin protein family (ficolin-1,

\section{KARGER}

Fax +4161306 1234

E-Mail karger@karger.ch

www.karger.com
(C) 2012 S. Karger AG, Basel

$1662-811 X / 13 / 0053-0242 \$ 38.00 / 0$

Accessible online at:

www.karger.com/jin
Prof. Dr. Peter Garred

Laboratory of Molecular Medicine, Department of Clinical Immunology Sect 7631, Rigshospitalet, Faculty of Health Sciences, University of Copenhagen Blegdamsvej 9, DK-2100 Copenhagen (Denmark)

E-Mail garred@post5.tele.dk 
ficolin-2 and ficolin-3, respectively) [3]. MBL and the ficolins form complexes with the MBL/ficolin-associated serine proteases named MASP-1, MASP-2 and MASP-3 and two nonenzymatic proteins named sMAP (MAp19) and MAP-1 (MAp44) [4]. MASP-1, MASP-3 and MAP-1 are all splice variants derived from the MASP1 gene, while MASP-2 and sMAP are splice variants derived from the MASP2 gene. MASP-2 has a defined role in the cleavage of $\mathrm{C} 4$ and $\mathrm{C} 2$ which leads to the formation of the C3-convertase enzyme complex [5]. Further downstream activation leads to cleavage and deposition of $\mathrm{C} 3 \mathrm{~b}$ and culminates in the formation of the terminal C5b-9 complement complex (TCC). On the other hand, MASP-1 cleaves $\mathrm{C} 2$, but not $\mathrm{C} 4$, and it has been shown that MASP1 enhances complement activation triggered by $\mathrm{MBL} / \mathrm{fi}$ colin-MASP-2 complexes, but cannot induce C3-convertase formation itself [6]. Recent findings show that about $75 \%$ of all C2 that becomes activated through lectin pathway activation is mediated by MASP-1 [7]. MASP-1 is, therefore, crucial for efficient activation of the lectin complement pathway. Regarding MASP-3, it has been reported that MASP-3 triggers the activation of the alternative complement pathway along with MASP-1, but this has only been shown in rodents [8]. While the function of the nonenzymatic protein named sMAP is unknown, in vitro data show that MAP-1, also known as MAp44, is a potent regulator of lectin complement pathway activation $[9,10]$.

Recently, three novel human collectins, collectin-10 (collectin liver 1, CL-L1 or CL-10), collectin-11 (collectin kidney 1, CL-K1 or CL-11) and collectin-12 (collectin placenta 1, CL-P1 or CL-12), have been identified and characterized after EST database search [11-13]. Among these molecules, only collectin-11 has been detected in plasma, but with a very low concentration of around 0.3 $\mu \mathrm{g} / \mathrm{ml}[14,15]$. It has been shown that collectin-11 binds to a broad spectrum of microorganisms, including bacteria, fungi and viruses, in a $\mathrm{Ca}^{2+}$-dependent manner with particular specificity for carbohydrates like L-fucose and D-mannose $[11,16]$. Collectin-11 has also been found to be associated with the MASPs [16, 17]. Furthermore, it has been shown that mutations in the genes encoding collectin-11 (COLEC11) as well as the serine protease MASP-3 (MASP1 gene) cause a human developmental syndrome, termed the 3MC (MalpuechMichels-Mingarelli-Carnevale) syndrome [18]. These evidences suggest a pivotal role of collectin-11 and MASP-3 not only in innate immune defense, but also in fundamental developmental processes. However, whether collectin-11 indeed may be a recognition molecule in the complement system has hitherto been unknown. Based on the similarities with MBL and the findings that collectin-11 may either be associated with MASP-1 or MASP-3 in plasma, we hypothesized that collectin-11 may function as a recognition molecule in the lectin complement pathway through interaction with the MASPs. In the present study, we used Candida albicans as a model of infection since collectin-11 has been shown to bind to this fungus [16]. Our results define collectin-11 as a new lectin complement pathway-activating molecule associated with the MASPs in addition to MBL and the ficolins.

\section{Materials and Methods}

\section{SDS-PAGE and Western Blot}

SDS-PAGE was perfomed using 4-12\% Bis-Tris gels (Invitrogen, Taastrup, Denmark), and separate bands were visualized by staining with Coomassie brilliant blue or transferred to PVDF membranes (Millipore, Hundested, Denmark) as previously described [19].

\section{Binding of Collectin-11 to C. albicans}

C. albicans (clinical isolate H29929; Statens Serum Institute, Denmark) [20] were washed and resuspended in TBS buffer (10 $\mathrm{mm}$ Tris, $150 \mathrm{~mm} \mathrm{NaCl}, 2.5 \mathrm{mM} \mathrm{CaCl}_{2}$, pH 7.4) containing $1 \%$ heat-inactivated FCS, then incubated with collectin-11 $(10 \mu \mathrm{g} / \mathrm{ml}$; R\&D Systems, Minneapolis, Minn., USA) at $37^{\circ} \mathrm{C}$ for 1 h. C. albicans were washed after each step in cold TBS/heat-inactivated FCS. Bound proteins were detected with rabbit anti-collectin-11 polyclonal antibody (Ab; PTGLAB, Manchester, UK) and FITCconjugated swine anti-rabbit IgG (Dako, Glostrup, Denmark), and finally analyzed with a BD FACSCalibur (Becton Dickinson, Bilthoven, The Netherlands). In some experiments, C. albicans were incubated with collectin-11 in the presence of EDTA (10 $\mathrm{mM})$, D-mannose (0.1 M), N-acetyl-D-glucosamine (GlcNAc; $0.1 \mathrm{M}$; all from Sigma, St. Louis, Mo., USA) or recombinant MBL $(5 \mu \mathrm{g} / \mathrm{ml})$. Binding of collectin-11 was determined as described above. Binding of MBL was assessed with anti-MBL monoclonal Ab (HYB131-11; BioPorto, Gentofte, Denmark). Recombinant MBL was produced as previously described [21]. In some experiments, the binding of collectin-11 was also tested on Aspergillus fumigatus instead of C. albicans as described above. The A. fumigatus strain, which is a clinical isolate, has been described previously [20].

\section{MASPs Associate with Collectin-11}

To determine whether the MASPs associate with collectin-11, full-length constructs of human recombinant MASP-1, MASP-2, MASP-3 and MAP-1 were expressed in CHO-DG44 cells and purified as described previously [19]. C. albicans were treated as above prior to incubation at $37^{\circ} \mathrm{C}$ for $1 \mathrm{~h}$ with or without collectin-11 $(10 \mu \mathrm{g} / \mathrm{ml})$, MASPs $(0.5 \mu \mathrm{g} / \mathrm{ml}$ of each MASP-1, MASP-2, MASP-3 and MAP-1) or a mixture of the proteins, respectively. Bound MASP-1, MASP-3 and MAP-1 were detected using an anti-MASP-1/3/MAP-1 monoclonal Ab (8B3; recognizing an epi- 
tope on the common heavy chain on all three molecules $[19,22])$ and FITC goat anti-mouse IgG (Dako), while MASP-2 was detected using a rat anti-MASP-2 monoclonal Ab (clone 8B5; Hycult, Uden, The Netherlands) and Alexa fluor 633 goat anti-rat IgG $(\mathrm{H}+\mathrm{L}$; Invitrogen). Alternatively, the association between MASPs and collectin-11 was also confirmed in ELISA by incubation of the MASPs (MASP-1, MASP-2 and MASP -3), MAP-1 (0.5 $\mu \mathrm{g} / \mathrm{ml}$ of each) or BSA $(5 \mu \mathrm{g} / \mathrm{ml})$ as a control to collectin-11 $(5 \mu \mathrm{g} /$ $\mathrm{ml})$ or MBL $(5 \mu \mathrm{g} / \mathrm{ml})$ immobilized in ELISA microtiter wells. Each bound MASP was detected with $8 \mathrm{~B} 3$ or $8 \mathrm{~B} 5$ antibodies, as described above.

\section{Complement Activation}

Complement $\mathrm{C} 4 \mathrm{~b}, \mathrm{C} 3 \mathrm{~b}$ and the TCC deposition were assessed as previously described [20]. In brief, C. albicans were incubated with collectin-11 $(10 \mu \mathrm{g} / \mathrm{ml})$ prior to the addition of MBL-defect serum (10\%) as a complement source. After washing, C4b, C3b and TCC deposition were detected by polyclonal anti-human $\mathrm{C} 4 \mathrm{c}$ Ab (Dako), anti-human C3c Ab (Dako) or monoclonal anti-human C5b-9 Ab (BioPorto), respectively, and finally analyzed by flow cytometry using FITC goat anti-mouse IgG (Dako). In some experiments, recombinant MASP-2 $(0.5 \mu \mathrm{g} / \mathrm{ml})$ and purified human C4b (10 $\mu \mathrm{g} / \mathrm{ml}$; CompTech, Tyler, Tex., USA) were applied as complement source instead of serum, and deposition of $\mathrm{C} 4$ after incubation for 15, 30 and 60 min was then determined with the anti-C4c antibody described above. Complement $\mathrm{C} 4 \mathrm{~b}, \mathrm{C} 3 \mathrm{~b}$ and TCC deposition were also assessed in the presence of mannose $(0.1 \mathrm{M})$. Alternatively, MBL-defect serum was first incubated with mannose-agarose (Sigma) in order to deplete collectin-11 from serum or control agarose (Sigma) prior to the use of serum as complement source. The content of collectin-11 in the supernatants after incubation was evaluated by Western blot. In addition, we spiked the depleted serum with $10 \mu \mathrm{g} / \mathrm{ml}$ of recombinant collectin-11.

\section{Statistical Analysis}

Statistical analysis was performed using Student's test and GraphPad Prism, version 5.0 (GraphPad Software, San Diego, Calif., USA).

\section{Results}

\section{Oligomerization of Collectin-11}

SDS-PAGE and Western blot analysis of recombinant collectin-11 under reducing and nonreducing conditions showed over $90 \%$ purity and a mixture of monomer and covalent oligomers ranging from dimers to dimers of trimeric subunit (online supplementary fig. 1A-D; see www. karger.com/doi/10.1159/000345356 for all online suppl. material). The activity was also identified and characterized elsewhere [11]. Western blot analysis under nonreducing conditions revealed that native collectin-11 present in the serum forms more complex oligomerization than recombinant collectin-11 (online suppl. fig. 1D).
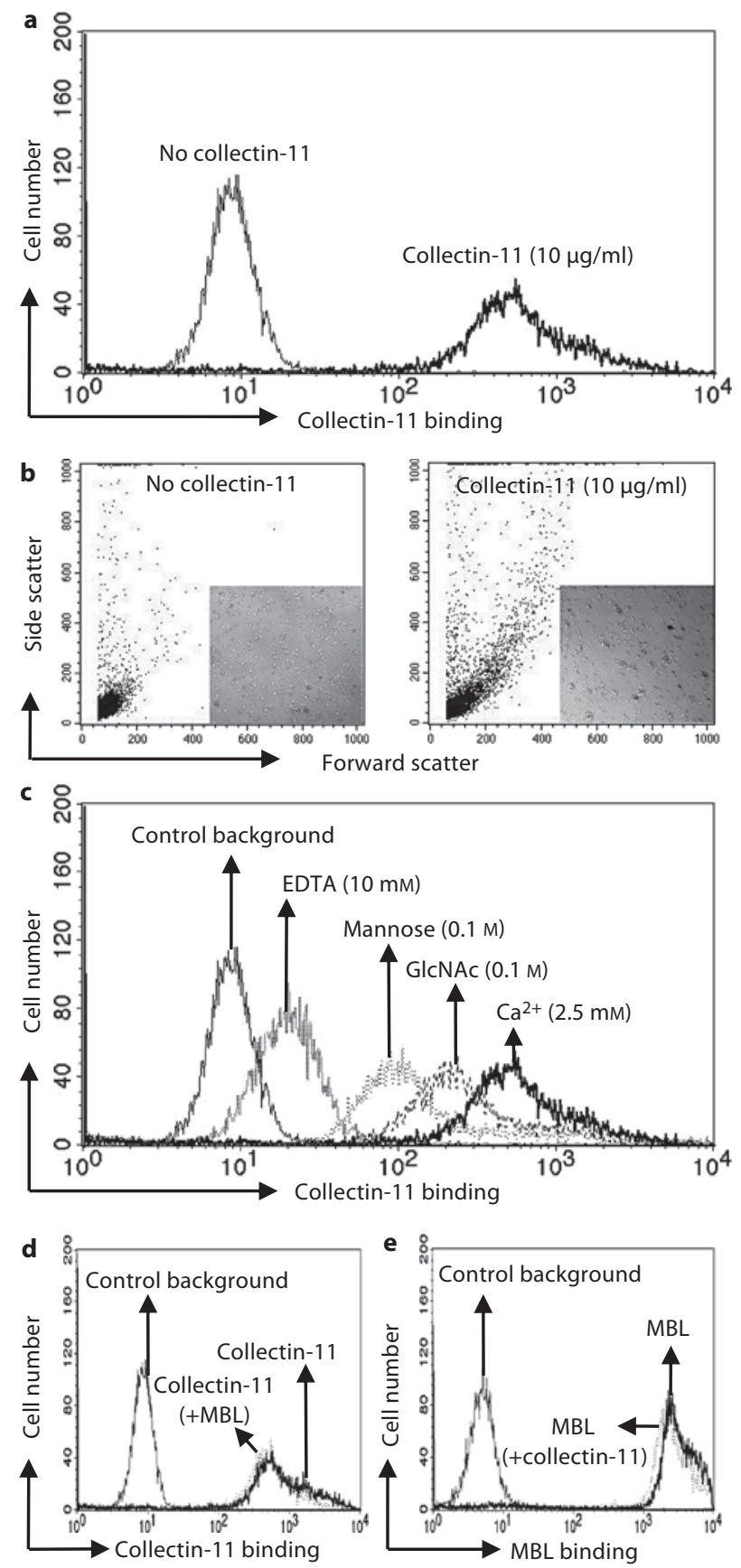

Fig. 1. Binding specificity of collectin-11 on C. albicans. a Binding of collectin-11 to C. albicans is shown. b Collectin-11-induced agglutination of C. albicans. Agglutination was assessed by change in forward and side scatter morphology. c Lectin activity of collectin-11 was confirmed by addition of EDTA, mannose or GlcNAc inhibiting the binding of collectin-11. d Binding of collectin-11 in the presence of MBL. e Binding of MBL in the presence of collectin-11. The mean fluorescence intensity was used to assess collectin-11 or MBL binding. Results are representative of at least three independent experiments. 

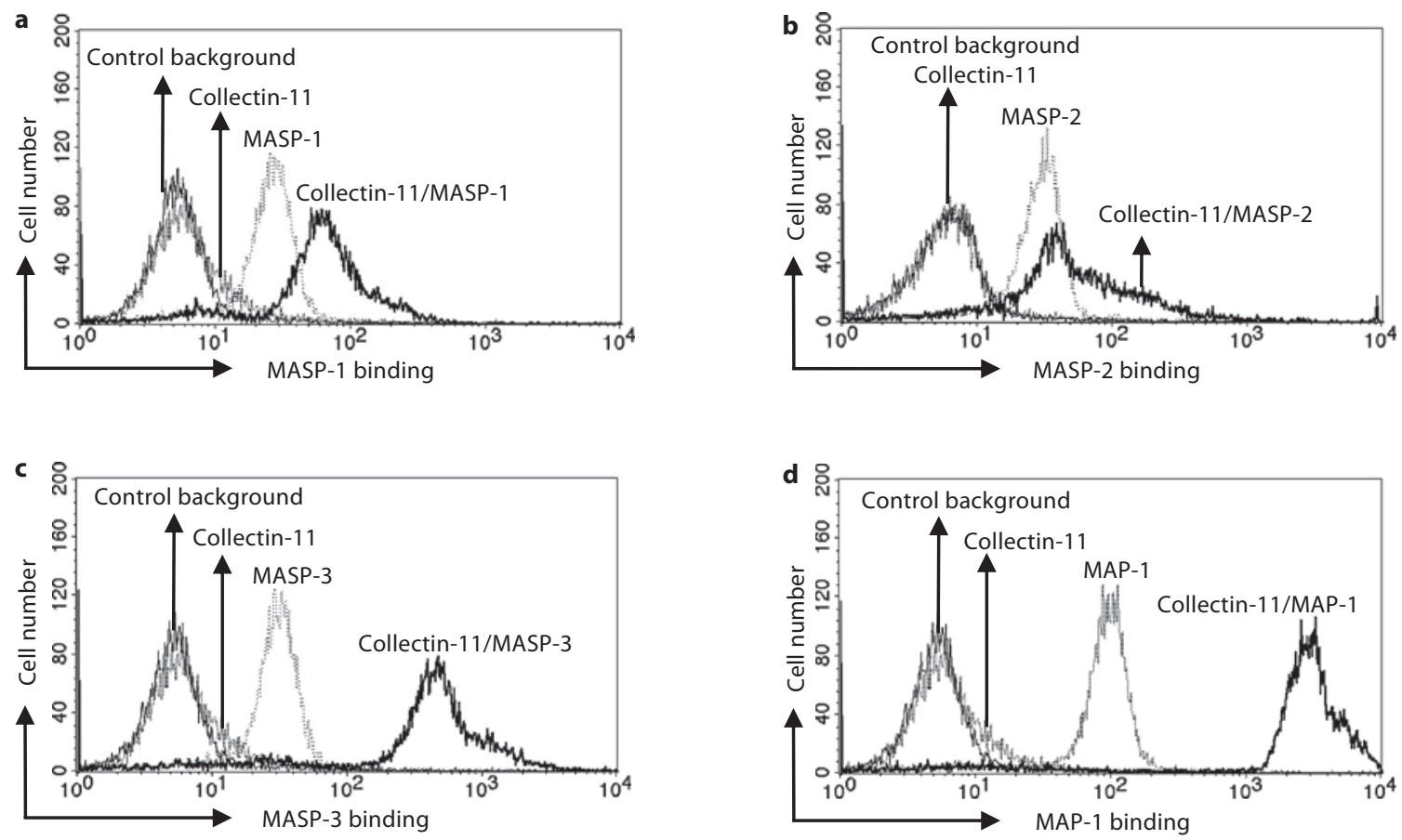

Fig. 2. Association of MASPs with collectin-11. a-d Association of MASPs with collectin-11 by flow cytometry. C. albicans were incubated with or without collectin-11 $(10 \mu \mathrm{g} / \mathrm{ml})$, MASPs $(0.5$ $\mu \mathrm{g} / \mathrm{ml}$ of each MASP and MAP-1) or a mixture of both, respectively. Bound MASPs were assessed by flow cytometry as described in Materials and Methods. The mean fluorescence intensity was used to assess MASP binding. Results are representative of at least three independent experiments. e Association of MASPs with collectin-11 in ELISA. ELISA wells coated with BSA $(5 \mu \mathrm{g} /$ $\mathrm{ml})$, collectin-11 $(5 \mu \mathrm{g} / \mathrm{ml})$ or MBL $(5 \mu \mathrm{g} / \mathrm{ml})$ were incubated with MASP-1, MASP-2, MASP-3 or MAP-1 (1 $\mu \mathrm{g} / \mathrm{ml}$ of each), respectively. Bound MASPs were detected as described in Materials and Methods. Results are expressed as means \pm SE from triplicate experiments. Results are representative of at least three independent experiments. ${ }^{*} \mathrm{p}<0.01$ vs. control.

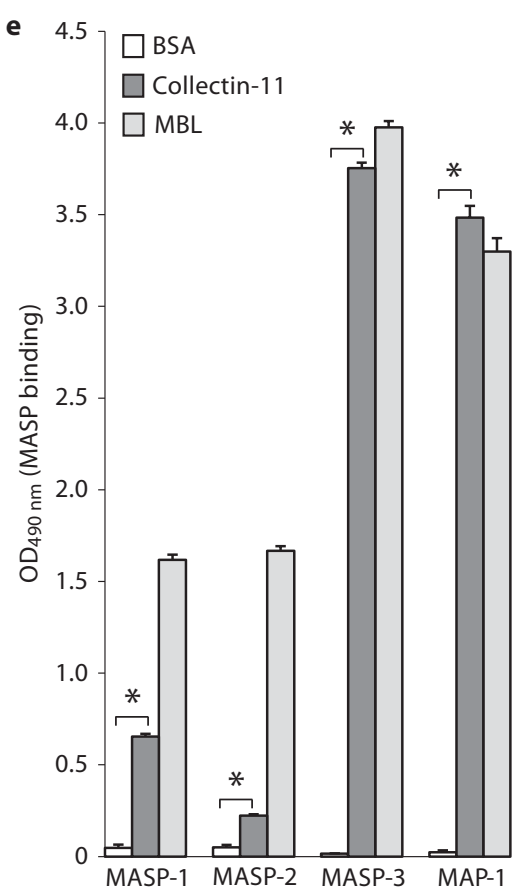


Binding of Collectin-11 to C. albicans and

\section{A. fumigatus}

To characterize the potential physiological relevance of collectin-11 in complement activation, C. albicans were used as a matrix and model of infection. As shown in fig. 1a, collectin-11 clearly bound to C. albicans, as reported recently [16]. We also found that collectin-11 could induce agglutination of C. albicans upon binding (fig. 1b). However, inclusion of EDTA, mannose or GlcNAc inhibited the binding of collectin-11 to C. albicans with different efficiency, showing a clear lectin activity of collectin-11 (fig. 1c). Interestingly, when collectin-11 was incubated together with MBL, MBL did not affect the binding of collectin-11 on C. albicans and vice versa (fig. 1d, e). Furthermore, we also found that collectin-11 bound A. fumigatus in a dose-dependent manner, whereas no inhibition of the binding was detected in the presence of EDTA, L-fucose or mannose (online suppl. fig. 2A, B).

\section{Formation of Collectin-11/MASP Complexes}

To determine whether MASPs were complexed with collectin-11, we performed flow cytometry. As shown in figure $2 \mathrm{a}-\mathrm{d}$, collectin-11 was associated with all MASPs, MASP-1 to MASP-3 and MAP-1, with differential extent. In comparison with MASP-3 or MAP-1, MASP-1 revealed a relatively weak association to collectin-11. This was also confirmed by ELISA (fig. 2e). Furthermore, we found that pathogenic C. albicans yeast adsorbed all MASPs on the surfaces in the absence of collectin- 11 .

Involvement of Collectin-11 in Complement Activation We next determined whether the collectin-11/MASP2 complex activates complement. When we reconstituted collectin-11/MASP-2 complexes on C. albicans by using recombinant proteins, addition of purified human $\mathrm{C} 4 \mathrm{en}$ hanced C4 deposition on C. albicans in a time-dependent manner (fig. 3). However, no significant signal was elicited when collectin-11 was applied alone. In contrast, in the absence of collectin-11, some MASP-2 could be absorbed to the fungus, which also elicited $\mathrm{C} 4$ deposition to a certain degree. However, no time dependency of this effect was observed (fig. 3). To investigate the physiological relevance, we also used MBL-defect whole serum as complement source and assessed the deposition of $\mathrm{C} 4 \mathrm{~b}$, C3b and TCC on C. albicans upon collectin-11 binding. This type of serum has previously been shown to contain only modest complement capacity when used with C. albicans without reconstitution with recombinant $\mathrm{MBL}$ [20]. As shown in figure $4 \mathrm{a}-\mathrm{c}$, an increase in the concentration of exogenously added collectin- 11 from 0 to 20

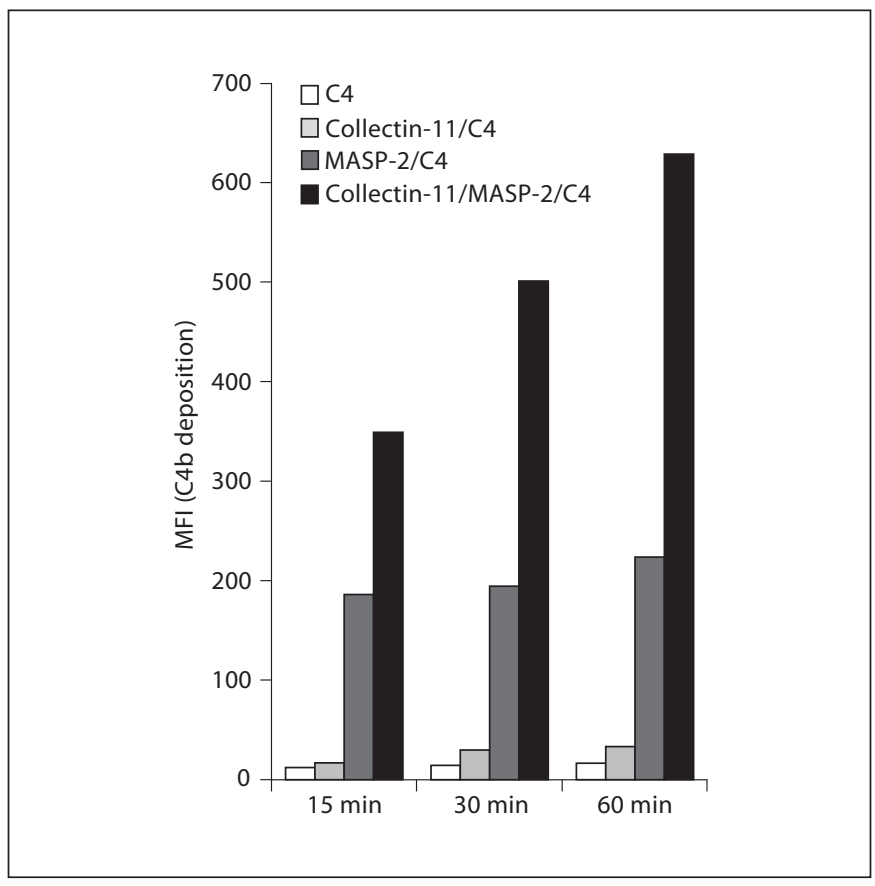

Fig. 3. Collectin-11/MASP-2 complex-induced C4 deposition. C. albicans were incubated with collectin-11 (10 $\mu \mathrm{g} / \mathrm{ml})$, MASP-2 $(0.5 \mu \mathrm{g} / \mathrm{ml})$ or a mixture of both proteins prior to addition of human purified C4 $(10 \mu \mathrm{g} / \mathrm{ml})$. C4 deposition after incubation for 15,30 and $60 \mathrm{~min}$ was determined by flow cytometry as described in Materials and Methods. The mean fluorescence intensity (MFI) was used to assess $\mathrm{C} 4$ deposition. Results are representative of at least three independent experiments.

$\mu \mathrm{g} / \mathrm{ml}$ was accompanied with a marked enhancement in C4b, C3b and TCC deposition on C. albicans, supporting the observations above using a pure serum-free system.

To determine the contribution of native serum collectin-11 to activation of the lectin complement pathway, we determined C4b, C3b and TCC deposition on C. albicans after incubation with MBL-defect serum in the presence of mannose. As shown in figure $5 \mathrm{a}-\mathrm{c}$, inclusion of mannose $(0.1 \mathrm{M})$ inhibited serum-mediated C4b, C3b and TCC deposition. To further verify the potential involvement of serum collectin-11, collectin-11 was depleted from serum using mannose-agarose beads. As a control, the serum was also incubated with control agarose beads in parallel. The serum level of collectin-11 was then evaluated by Western blot under reducing conditions showing that adding mannose-agarose mediated depletion, while control agarose did not (fig. $5 \mathrm{~d}$, inset). As shown in fig. $5 \mathrm{~d}-\mathrm{f}$, depletion of native collectin-11 from the serum inhibited $\mathrm{C} 4 \mathrm{~b}, \mathrm{C} 3 \mathrm{~b}$ and TCC deposition compared with control serum. No apparent differences were de- 


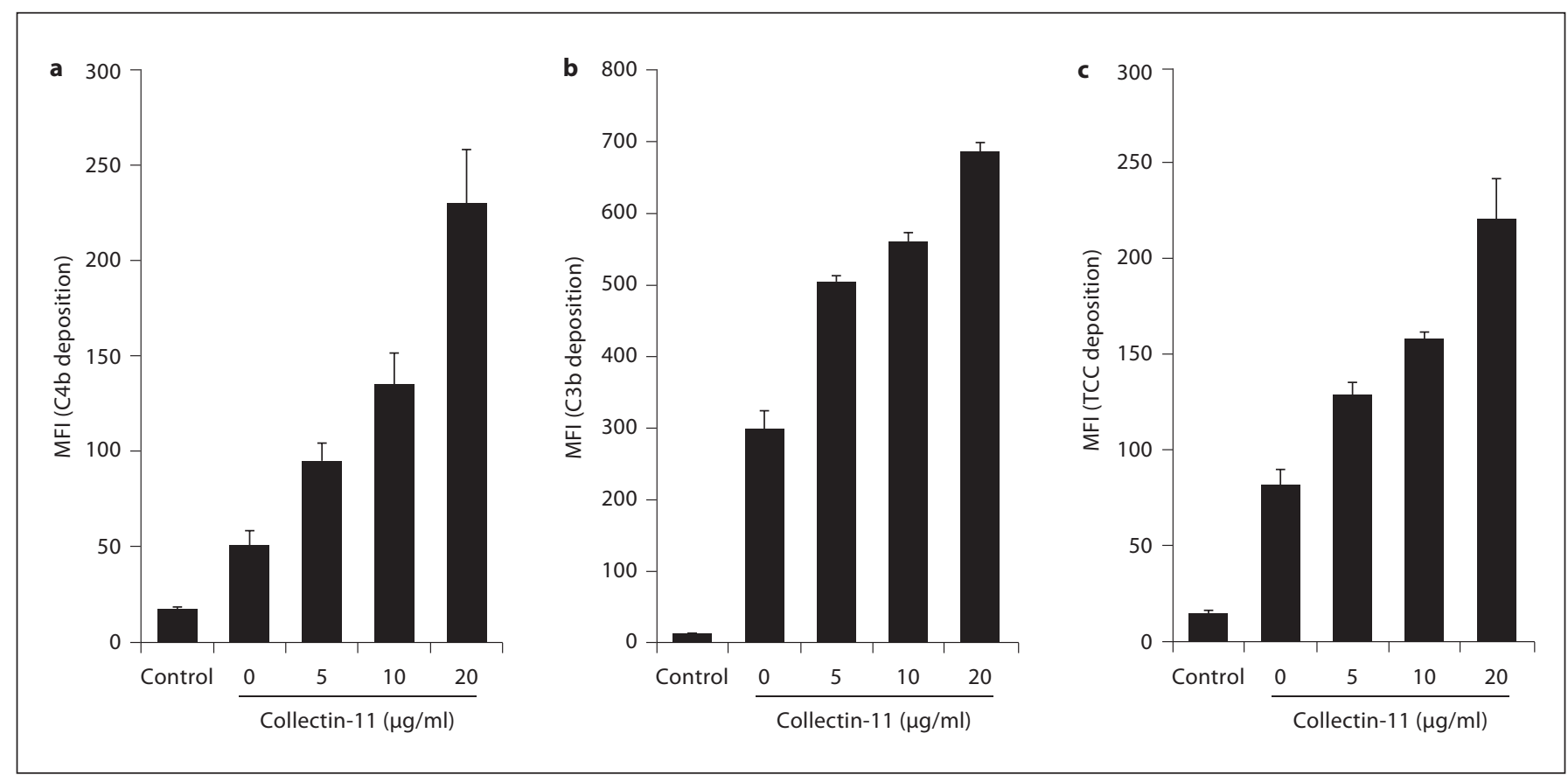

Fig. 4. Collectin-11-induced complement activation. C. albicans were incubated with increasing concentrations of collectin-11 prior to induction of complement activation by MBL-defect whole serum (10\%). C4b (a), C3b (b) or TCC (c) deposition was determined by flow cytometry as described in Materials and Methods.
The mean fluorescence intensity (MFI) was used to assess complement activation. Data are expressed as means \pm SE from triplicate experiments. Results are representative of three independent experiments. tected in C4b, C3b or TCC deposition between the sera treated with or without control agarose beads (data not shown).

When we added recombinant collectin-11 to the depleted serum, we were able to restore $\mathrm{C} 4 \mathrm{~b}, \mathrm{C} 3 \mathrm{~b}$ or TCC deposition (fig. $5 \mathrm{~d}-\mathrm{f}$ ). When collectin-11 was bound to A. fumigatus, no collectin-11-dependent complement deposition was observed (data not shown).

\section{Discussion}

Collectins play important roles in innate immunity due to their capacity to induce humoral and cellular effector defense functions [2]. Recently, a novel collectin, collectin-11, also named CL-K1 or CL-11, has been described $[11,14,16]$. Collectin-11 has been shown to be associated with the MASPs $[16,17]$. In the present study, we can also demonstrate that collectin-11 associates with both MASPs (MASP-1, MASP-2 and MASP-3) as well as the lectin complement regulator MAP-1. More importantly, we could demonstrate conclusively for the first time that collectin-11 mediates complement activation via the lectin route.

Consistent with previous immunoblotting data [16], our flow cytometry data clearly show that collectin-11 recognizes $C$. albicans most likely via its CRD domain because the binding could be inhibited by EDTA, mannose and GlcNAc, suggesting that this is a classical calcium-dependent interaction to carbohydrate residues present on C. albicans. However, particularly interesting was the observation that collectin-11 binding was not inhibited by MBL and vice versa, implying that in terms of the fine pathogen-associated molecular pattern specificity these molecules do not compete with each other and in protection against certain microorganisms may compensate for each other. Taken together these findings clearly show that molecules like collectin-11 may compensate for MBL deficiency and explain why MBL may be partly redundant [23]. Due to differences in fine specificity, it is also conceivable that collectin-11 may bind to microorganisms with which MBL cannot interact and vice versa. Indeed, it has been reported that MBL does not bind to some investigated Streptococcus pneumonia strains while 


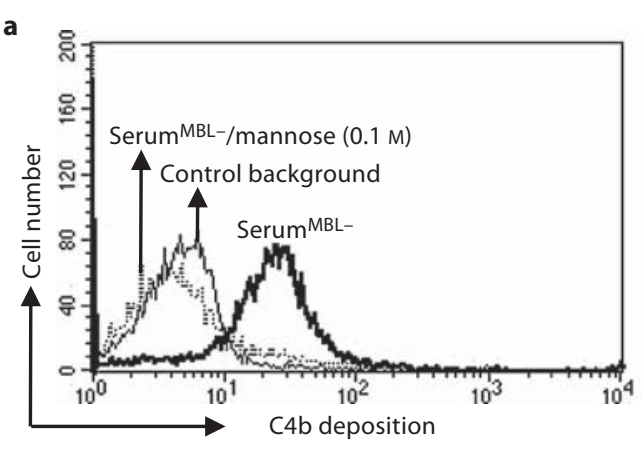

b

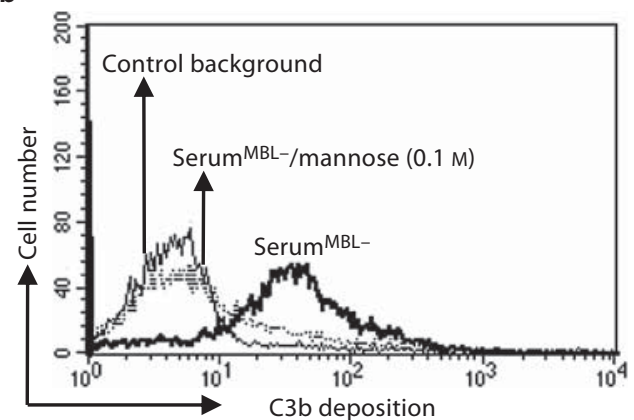

c

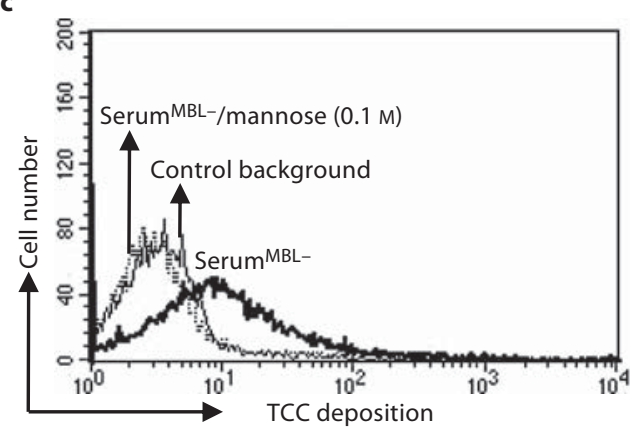

d
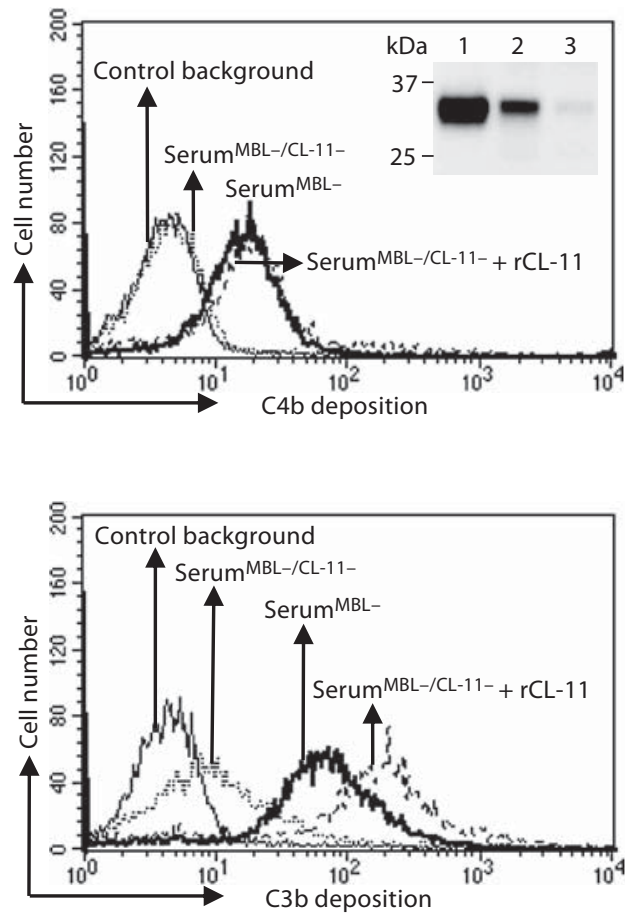

$\mathbf{f}$

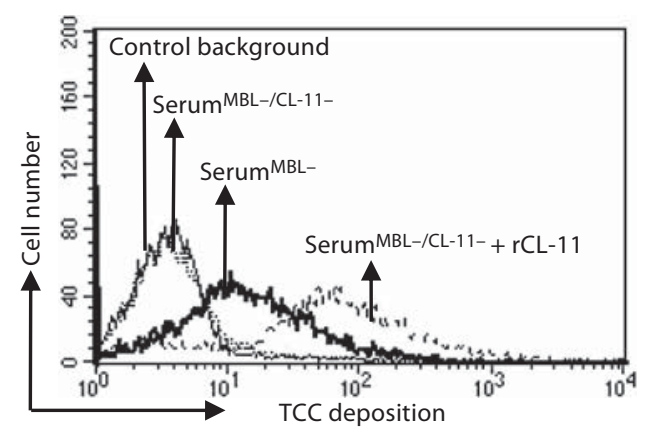

Fig. 5. Activity of native collectin-11 in relation to complement activation. C. albicans were incubated with MBL-defect serum (serum $\left.^{\mathrm{MBL}-}, 10 \%\right)$ in the absence or presence of mannose $(0.1 \mathrm{M})$ or with MBL-defect serum treated with either mannose-agarose beads or control agarose beads. In addition, we used MBL-defect serum depleted for native collectin-11 (serum ${ }^{\mathrm{MBL}-/ \mathrm{CL}-11-}$ ) that was restored with recombinant collectin-11 (rCL-11; $10 \mu \mathrm{g} / \mathrm{ml}$ ). C4b $(\mathbf{a}, \mathbf{d}), \mathrm{C} 3 \mathrm{~b}(\mathbf{b}, \mathbf{e})$ or TCC $(\mathbf{c}, \mathbf{f})$ deposition was then determined for both mannose-introduced experiments $(\mathbf{a}-\mathbf{c})$ and effect of de-

a clear binding of collectin-11 was observed [17]. A novel antimicrobial feature we observed regarding collectin-11 was its capacity to agglutinate $C$. albicans even without the presence of serum or involvement of complement. Thus, collectin-11 may have a role in innate immune pro- pletion (d-f) by flow cytometry as described in Materials and Methods. Depletion of native collectin-11 from MBL-defect serum was analyzed by Western blot under reducing conditions (d: inset). Lane 1 = Recombinant collectin-11; lane 2 = the serum treated with control agarose beads; lane $3=$ the serum treated with mannose-agarose beads; serum ${ }^{\mathrm{MBL}-}=\mathrm{MBL}$-defect serum; serum $^{\text {MBL-/CL-11- }}=$ MBL-defect serum depleted for native collectin-11. Results are representative of three independent experiments that yielded similar results. 
migatus was calcium independent and could not be inhibited by L-fucose or mannose, suggesting that the interaction was not via the classical calcium-dependent CRD structures. Interestingly, this also seems to be the case with the previously reported interaction between collectin-11 and DNA [16]. Moreover, interaction between collectin-11 and A. fumigatus did not lead to complement activation.

Using the ELISA platform and flow cytometry, we could show that collectin-11 associated with MASP-1, MASP-2, MASP-3 and MAP-1, but to varying extent. As reported previously, the binding motif of MASPs in MBL has been identified to involve a sequence stretch: HypGly-Lys-Xaa-Gly-Pro, where $\mathrm{Lys}^{55}$ is believed to have an essential role and is conserved in a variety of species of MBL and ficolins [24, 25]. It has also been shown that only the mutation in Lys ${ }^{55}$ in the collagen-like domain of MBL, but not mutation in either $\mathrm{Pro}^{53}$ or Leu ${ }^{56}$, affects the MASP association to a great extent, indicating that Pro ${ }^{53}$ or Leu ${ }^{56}$ are apparently not critical [25]. Different from MBL, collectin-11 possesses a reconstituted amino acid sequence conserved in a variety of species: His-Gly-LysIle-Gly-Pro, instead of the MASP binding motif of MBL and the ficolins. However, the key lysine residue in collectin-11 which corresponds to the critical Lys ${ }^{55}$ in MBL (Lys ${ }^{57}$ in ficolin-2 or Lys ${ }^{47}$ in ficolin-3) is a feature providing a theoretical assumption of the critical motif via which collectin-11 may associate with the MASPs $[16,17$, 26]. However, only studies using site-directed mutagenesis and expression of mutated collectin-11 may shed detailed light on this assumption.

Our results show that recombinant MASP-2, the activator of $\mathrm{C} 4$ in the lectin complement pathway, was able to enhance deposition of $\mathrm{C} 4 \mathrm{~b}$ on C. albicans in the presence of recombinant collectin-11. In a more physiologically relevant setting, we used MBL-defect serum as MASP and complement source to elucidate whether anchorage of collectin-11 on C. albicans could enhance complement deposition. Our results clearly demonstrate that $\mathrm{C} 4 \mathrm{~b}$ deposition was enhanced in a collectin-11 dose-dependent fashion, which also led to enhancement of C3b and TCC deposition. In addition, when we blocked binding of native collectin-11 with mannose, no complement deposition was observed in MBL-defect serum. This was also noted when collectin-11 was depleted from serum, while when we added back recombinant collectin-11 the complement deposition activity was restored. These results provide proof of concept that collectin-11 functions as a recognition molecule in the lectin complement pathway in addition to MBL and the ficolins.
Defects in the genes encoding either collectin-11 or MASP-3 have been shown to cause the $3 \mathrm{MC}$ development syndrome [18]. The $3 \mathrm{MC}$ syndrome is a unifying term encompassing the overlapping Carnevale, Mingarelli, Malpuech and Michels syndromes. These rare autosomal recessive disorders exhibit a spectrum of developmental features, including characteristic facial dysmorphism, cleft lip and/or palate, craniosynostosis, learning disability, and genital, limb and vesicorenal anomalies. However, it is difficult to reconcile that the 3MC syndrome should be caused by a complement defect per se. COLEC11 RNA knockdown studies using embryonal zebra fish indicated that collectin-11 deficiency hampered neural crest cell migration [18]. Thus, it is likely that collectin-11 and MASP-3 also may have important physiological roles outside what we generally regard as the functions of the complement system.

The capability to evade immune recognition and attack is widely used by pathogens [27]. C. albicans possess several strategies to circumvent the complement system [28]. Thus, it is interesting to note that MASP-2 binds to pathogenic C. albicans without support of bridging molecules, which results in some degree of $\mathrm{C} 4$ deposition. Further studies are necessary to elucidate whether this side observation is biologically relevant and represents a true evasion mechanism, and/or whether C. albicans contains MASP-binding molecules.

In summary, we demonstrate that collectin-11 is present in association with MASP-1, MASP-2, MASP-3 and MAP-1, and define collectin-11 as a novel initiator molecule of the lectin complement pathway activation upon recognition of microorganisms. Thus, collectin-11 may be regarded as the fifth recognition molecule of the lectin pathway besides MBL, ficolin-1, ficolin-2 and ficolin-3.

\section{Acknowledgments}

This work was supported by grants from the Alfred Benzon Foundation, the Novo Nordisk Research Foundation, the Danish Cancer Society, the Svend Andersen Research Foundation, the Research Foundations of the Capital Region of Denmark and Rigshospitalet and the Danish Medical Research Council.

\section{Disclosure Statement}

The authors declare no conflict of interest. 


\section{References}

1 Medzhitov R, Janeway C Jr: Innate immunity. N Engl J Med 2000;343:338-344.

$>2$ van de Wetering JK, van Golde LM, Batenburg JJ: Collectins: players of the innate immune system. Eur J Biochem 2004;271:12291249.

-3 Garred P, Honore C, Ma YJ, Munthe-Fog L, Hummelshoj T: MBL2, FCN1, FCN2 and FCN3 - the genes behind the initiation of the lectin pathway of complement. Mol Immunol 2009;46:2737-2744.

$\checkmark 4$ Yongqing T, Drentin N, Duncan RC, Wijeyewickrema LC, Pike RN: Mannose-binding lectin serine proteases and associated proteins of the lectin pathway of complement: two genes, five proteins and many functions? Biochim Biophys Acta 2012; 1824:253-262.

$>5$ Thiel S, Vorup-Jensen T, Stover CM, Schwaeble W, Laursen SB, Poulsen K, Willis AC, Eggleton P, Hansen S, Holmskov U, Reid KB, Jensenius JC: A second serine protease associated with mannan-binding lectin that activates complement. Nature 1997;386:506510.

6 Takahashi M, Iwaki D, Kanno K, Ishida Y, Xiong J, Matsushita M, Endo Y, Miura S, Ishii N, Sugamura K, Fujita T: Mannosebinding lectin (MBL)-associated serine protease (MASP)-1 contributes to activation of the lectin complement pathway. J Immunol 2008; 180:6132-6138.

7 Heja D, Kocsis A, Dobo J, Szilagyi K, Szasz R, Zavodszky P, Pal G, Gal P: Revised mechanism of complement lectin-pathway activation revealing the role of serine protease MASP-1 as the exclusive activator of MASP2. Proc Natl Acad Sci USA 2012;109:1049810503.

$>8$ Iwaki D, Kanno K, Takahashi M, Endo Y, Matsushita M, Fujita T: The role of mannosebinding lectin-associated serine protease-3 in activation of the alternative complement pathway. J Immunol 2011;187:3751-3758.

$>9$ Skjoedt MO, Hummelshoj T, Palarasah Y, Honore C, Koch C, Skjodt K, Garred P: A novel mannose-binding lectin/ficolin-associated protein is highly expressed in heart and skeletal muscle tissues and inhibits complement activation. J Biol Chem 2010;285: 8234-8243.

$>10$ Degn SE, Hansen AG, Steffensen R, Jacobsen C, Jensenius JC, Thiel S: MAp44, a human protein associated with pattern recognition molecules of the complement system and regulating the lectin pathway of complement activation. J Immunol 2009;183:7371-7378.
11 Keshi H, Sakamoto T, Kawai T, Ohtani K, Katoh T, Jang SJ, Motomura W, Yoshizaki T, Fukuda M, Koyama S, Fukuzawa J, Fukuoh A, Yoshida I, Suzuki Y, Wakamiya N: Identification and characterization of a novel human collectin CL-K1. Microbiol Immunol 2006;50:1001-1013.

12 Ohtani K, Suzuki Y, Eda S, Kawai T, Kase T, Keshi H, Sakai Y, Fukuoh A, Sakamoto T, Itabe H, Suzutani T, Ogasawara M, Yoshida I, Wakamiya N: The membrane-type collectin CL-P1 is a scavenger receptor on vascular endothelial cells. J Biol Chem 2001;276: 44222-44228.

13 Ohtani K, Suzuki Y, Eda S, Kawai T, Kase T, Yamazaki H, Shimada T, Keshi H, Sakai Y, Fukuoh A, Sakamoto T, Wakamiya N: Molecular cloning of a novel human collectin from liver (CL-L1). J Biol Chem 1999;274: 13681-13689.

14 Yoshizaki T, Ohtani K, Motomura W, Jang SJ, Mori K, Kitamoto N, Yoshida I, Suzuki Y, Wakamiya N: Comparison of human blood concentrations of collectin kidney 1 and mannan-binding lectin. J Biochem 2012;151: 57-64.

15 Selman L, Henriksen ML, Brandt J, Palarasah Y, Waters A, Beales PL, Holmskov U, Jorgensen TJ, Nielsen C, Skjodt K, Hansen S: An enzyme-linked immunosorbent assay (ELISA) for quantification of human collectin 11 (CL-11, CL-K1). J Immunol Methods 2012; 375:182-188.

16 Hansen S, Selman L, Palaniyar N, Ziegler K, Brandt J, Kliem A, Jonasson M, Skjoedt MO, Nielsen O, Hartshorn K, Jorgensen TJ, Skjodt K, Holmskov U: Collectin 11 (CL-11, CL-K1) is a MASP-1/3-associated plasma collectin with microbial-binding activity. J Immunol 2010;185:6096-6104.

17 Ali YM, Lynch NJ, Haleem KS, Fujita T, Endo Y, Hansen S, Holmskov U, Takahashi K, Stahl GL, Dudler T, Girija UV, Wallis R, Kadioglu A, Stover CM, Andrew PW, Schwaeble WJ: The lectin pathway of complement activation is a critical component of the innate immune response to pneumococcal infection. PLoS Pathog 2012;8:e1002793.

-18 Rooryck C, Diaz-Font A, Osborn DP, Chabchoub E, Hernandez-Hernandez V, Shamseldin H, Kenny J, Waters A, Jenkins D, Kaissi AA, Leal GF, Dallapiccola B, Carnevale F, Bitner-Glindzicz M, Lees M, Hennekam R, Stanier P, Burns AJ, Peeters H, Alkuraya FS, Beales PL: Mutations in lectin complement pathway genes COLEC11 and MASP1 cause 3MC syndrome. Nat Genet 2011;43:197-203.
19 Skjoedt MO, Palarasah Y, Munthe-Fog L, Jie Ma Y, Weiss G, Skjodt K, Koch C, Garred P: $\mathrm{MBL}$-associated serine protease-3 circulates in high serum concentrations predominantly in complex with Ficolin-3 and regulates Ficolin-3 mediated complement activation. Immunobiology 2010;215:921-931.

20 Ma YJ, Doni A, Skjoedt MO, Honore C, Arendrup M, Mantovani A, Garred P: Heterocomplexes of mannose-binding lectin and the pentraxins PTX3 or serum amyloid P component trigger cross-activation of the complement system. J Biol Chem 2011;286: 3405-3417.

21 Larsen F, Madsen HO, Sim RB, Koch C, Garred P: Disease-associated mutations in human mannose-binding lectin compromise oligomerization and activity of the final protein. J Biol Chem 2004;279:21302-21311.

$\checkmark 22$ Skjoedt MO, Hummelshoj T, Palarasah Y, Hein E, Munthe-Fog L, Koch C, Skjodt K, Garred P: Serum concentration and interaction properties of $\mathrm{MBL} /$ ficolin associated protein-1. Immunobiology 2011;216:625632.

23 Garred P, Larsen F, Seyfarth J, Fujita R, Madsen HO: Mannose-binding lectin and its genetic variants. Genes Immun 2006;7:85-94.

24 Wallis R: Interactions between mannosebinding lectin and MASPs during complement activation by the lectin pathway. Immunobiology 2007;212:289-299.

25 Teillet F, Lacroix M, Thiel S, Weilguny D, Agger T, Arlaud GJ, Thielens NM: Identification of the site of human mannan-binding lectin involved in the interaction with its partner serine proteases: the essential role of Lys55. J Immunol 2007;178:5710-5716.

26 Lacroix M, Dumestre-Perard C, Schoehn G, Houen G, Cesbron JY, Arlaud GJ, Thielens NM: Residue Lys57 in the collagen-like region of human L-ficolin and its counterpart Lys47 in H-ficolin play a key role in the interaction with the mannan-binding lectin-associated serine proteases and the collectin receptor calreticulin. J Immunol 2009;182: 456-465.

27 Lambris JD, Ricklin D, Geisbrecht BV: Complement evasion by human pathogens. Nat Rev Microbiol 2008;6:132-142.

28 Zipfel PF, Skerka C, Kupka D, Luo S: Immune escape of the human facultative pathogenic yeast Candida albicans: the many faces of the Candida Pral protein. Int J Med Microbiol 2011;301:423-430. 